This item was submitted to Loughborough's Research Repository by the author.

Items in Figshare are protected by copyright, with all rights reserved, unless otherwise indicated.

\title{
Surface conditioning of carbon-fiber ceramic rotors against organic pads
}

PLEASE CITE THE PUBLISHED VERSION

http://digitallibrary.sae.org/content/2012-01-1833

PUBLISHER

(C) SAE International

VERSION

AM (Accepted Manuscript)

LICENCE

CC BY-NC-ND 4.0

REPOSITORY RECORD

Swarbrick, Arthur L., and Houzheng Wu. 2012. "Surface Conditioning of Carbon-fiber Ceramic Rotors Against Organic Pads". figshare. https://hdl.handle.net/2134/10058. 
This item was submitted to Loughborough's Institutional Repository (https://dspace.lboro.ac.uk/) by the author and is made available under the following Creative Commons Licence conditions.

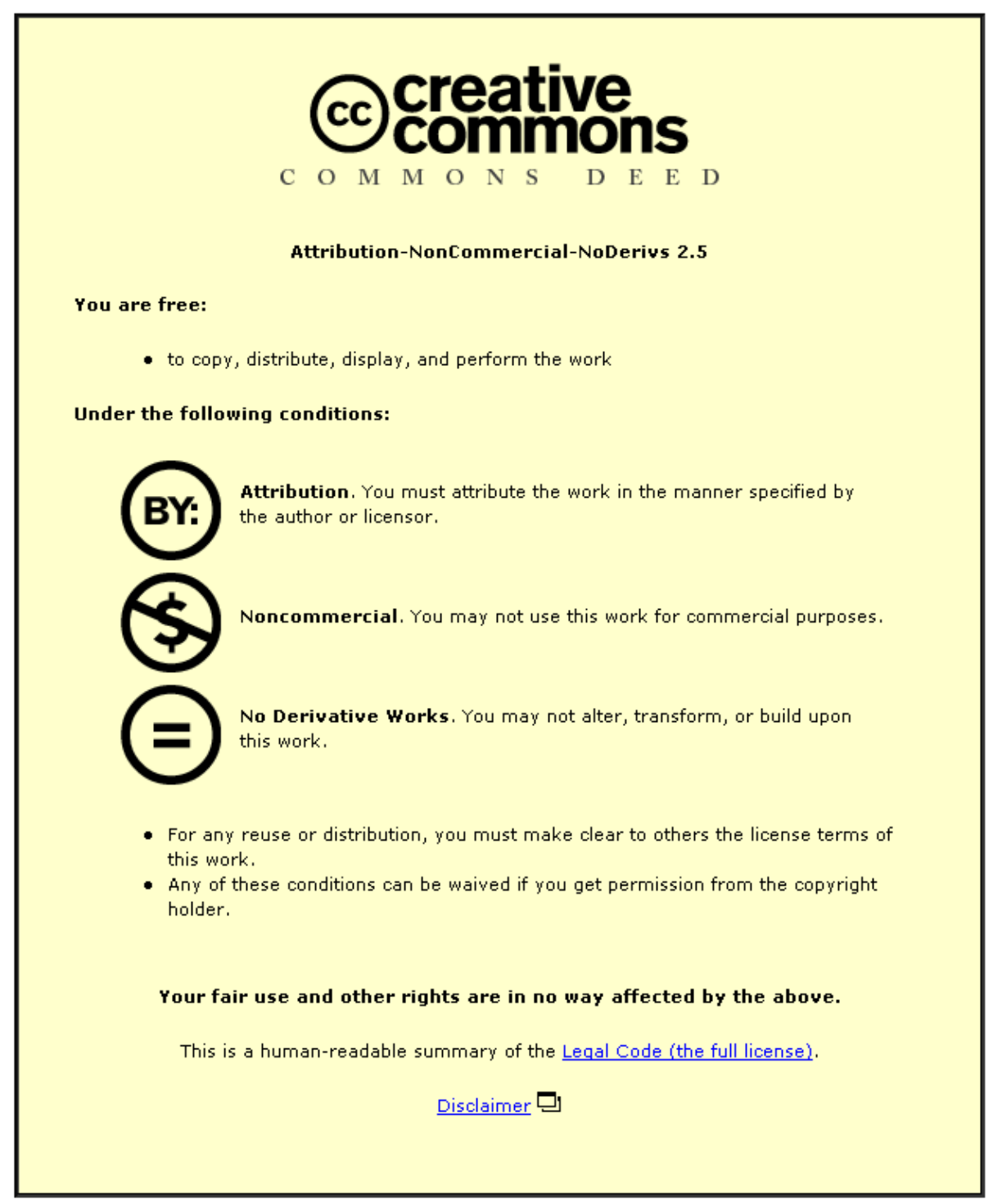

For the full text of this licence, please go to: http://creativecommons.org/licenses/by-nc-nd/2.5/ 


\title{
Surface Conditioning of Carbon-Fiber Ceramic Rotors against Organic Pads
}

\author{
Author, co-author (Do NOT enter this information. It will be pulled from participant tab \\ in MyTechZone)
}

Affiliation (Do NOT enter this information. It will be pulled from participant tab in MyTechZone)

Copyright (C) 2012 SAE International

\begin{abstract}
Previous research has highlighted that the formation of a sustained friction film, desired for stable and predictable friction performance, is highly dependent upon the region of the substrate (CMC) being examined. In attempt to improve the friction performance, notably bedding-in, research at LU has been developing coatings aimed at ensuring friction film development across the substrate. This paper focuses on the performance of one of these coating formulations, and examines the performance of this on a laboratory scale dynamometer. Subsequently, the coating has then been applied to a full size brake disc, as used on a prestige vehicle, for dynamometer testing at an industry scale for comparative purposes.
\end{abstract}

On both lab and full scale samples the bedding performance shows improvements over the standard material, and at the full scale the coating indicates improved stability of subsequent friction performance through a modified AK Master test schedule. Post-test OM and SEM characterization of the friction surfaces shows that friction film formation has improved over the standard samples, and EDS elemental analysis indicates the presence of the original coating remaining within the formed friction film.

Further characterization of the friction surface aims to identify the interactions between the coating and the substrate before and after friction testing.

\section{INTRODUCTION}

Carbon fiber reinforced ceramic composites (CFRCC) have been increasingly used on many sports and prestige vehicles as brake rotors within the past decade, and their adoption by OEM's and consumers is increasing. Their relative benefits over iron-based alternatives are well identified [1]: reduced density, low wear rates and improved braking performance at elevated temperatures. Conceivable drawbacks are few: primarily the high purchase cost to consumers, driven by long duration and cost of manufacture; concerns including cold start and bedding performance, and oxidation at extreme operating temperatures, under certain braking circumstances.

The work carried out by Wang \& Wu [Paper 1] has identified that the fundamental friction performance of the material is largely dictated by the nature of constituents and heterogeneous microstructure of the composites. This inherent property of the composite material leads to unevenly distributed third body layer formation (TBL) on the rotor surface, commonly understood to be a crucial factor in determining the friction performance of a couple. In modifying the surface of the rotor prior to friction, it is anticipated that the deposition of the TBL and subsequent friction performance can be controlled and improved.

Theoretically the use of surface modifications to improve this material's suitability for this application can be achieved using two methodologies, physically and chemically. By the addition of a formulated coating to the surface of the CFRCC, it may be possible to improve the deposition of the TBL and its bonding with the rotor, forming a hybrid-TBL layer. The subsequent friction performance of the couple should be largely dependent on the layer, if sustainable. In this paper, we will validate if a surface conditioning coating could improve the friction performance of CFRCC rotors. 


\section{METHODOLOGY}

\subsection{SAMPLE PREPARATION}

Small disc samples were manufactured in the Loughborough University Advanced Friction Materials (LU AFM) lab, machined from commercially supplied carbon fiber reinforced carbon/silicon carbide $\left(\mathrm{C}_{\mathrm{f}} / \mathrm{C}-\mathrm{SiC}\right)$, often called carbon silicon carbide (CSiC), material to $\varnothing 60 \mathrm{~mm} \times 9 \mathrm{~mm}$ (see Figure 1). After machining, each sample was ultrasonically cleaned in water (5 minutes) and acetone (5 minutes) to remove any loose debris, or cutting lubricants from machining. Previous work had been conducted using machine polished samples to enable improved imaging during the characterization phase of investigation. For this work, the friction surface of each sample has been finished to the original manufacturers' specification, to keep in-line with the full scale discs which is also finished to the manufacturers' specification.

The friction material (pad) samples were supplied from a commercially supplied organic based formulation and were machined at LU AFM to outer diameter $\varnothing 50 \mathrm{~mm}$, inner diameter $\varnothing 40 \mathrm{~mm}$. The ring was then machined to produce two arcs as shown in Figure 1.
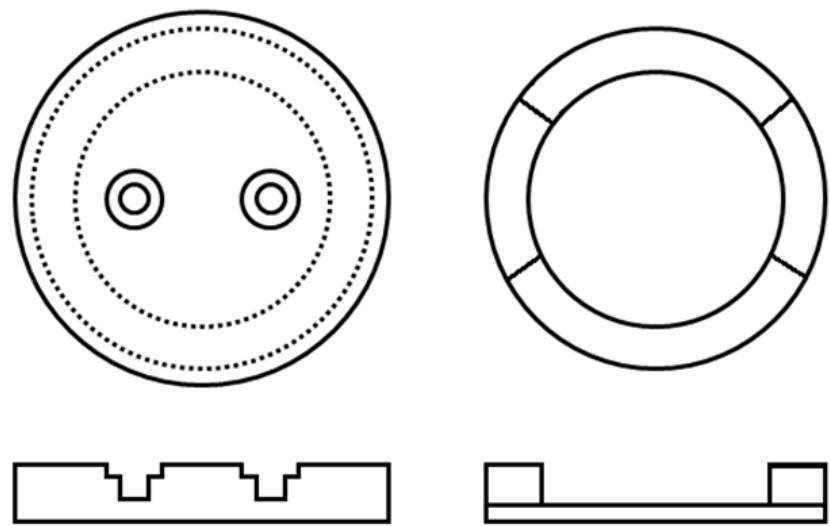

Figure 1 - A schematic of the discs (left) and pads (right) for small scale testing, as machined at LU AFM. Note: the dashed lines indicate the location of the friction track on the disc (not to scale)

\subsection{COATING PROCESSING}

The coating was produced from mixing a graded particle size non-ferrous oxide particles with phosphoric acid, and dosed with boric acid. The coating was then applied to the friction surface of the rotor by brushing, with a final scrape smoothing the brush lines in the coating in an attempt to reduce/eliminate disc thickness variation DTV issues. The coating then underwent a curing process over 96 hours to produce a low temperature cured ceramic-like coating at the surface of the rotor. Post curing optical and/or scanning electron microscopy (OM/SEM) imaging indicated a thin coating across the surface, $\sim 10 \mu \mathrm{m}$ in depth, is deposited. This procedure was identical for the large scale disc and was carried out on site at LU, before transporting to the industry partner for testing.

\subsection{TESTING \& CHARACTERISATION PROCEDURE}

The lab scale testing was carried out on a pneumatically operated dynamometer, the operational details of which can be found outlined in previous work (YW/HW paper 1). The test schedule consisted of 200 accumulated braking stops. Each stop was initiated by a foot pedal, applying pneumatic pressure to the pad and thus to the surface of the disc at a constant pressure of $0.9 \mathrm{MPa}$; the rotational speed of the outer edge was $\sim 25 \mathrm{~m} / \mathrm{s}$, inner edge was $\sim 21 \mathrm{~m} / \mathrm{s}$ at the beginning of each stop. The disc was slowed to stationary and the applied torque measured through a calibrated load cell and logged at a $50 \mathrm{~Hz}$ frequency throughout the stop. The coefficient of friction $(\mu)$ value was then calculated from the average of these logged values for each stop.

The full scale testing was carried out at Federal Mogul, Derbyshire, UK. The test schedule used has been heavily based around the industry standard AK Master Test schedule, with a few additional sections to include temperature excursions and wet performance runs.

Page 2 of 9 
The organic pad lining material used throughout out both small and large scale testing was from the same organic based formulation, and contains a wide spectrum of ingredients including ferrous and non-ferrous metals, lubricants, abrasives and fillers as well as organic fibers and binders. For the full scale test the material was mounted onto a standard OEM back plate, and for the small scale samples the material was mounted on to custom brass back plates using standard techniques.

Pre \& post-test characterization was carried out on the lab scale samples, with post-test analysis carried out on $\phi 4 \mathrm{~mm}$ core samples drilled from the fill-sized disc surface. Optical microscopy (OM) (MEF3, Reichert-Jung, Wien, Austria) was used under polarized light conditions to reveal the variations in the microstructure for each disc. Scanning electron microscopy (SEM) imaging was also conducted alongside EDS analysis on a field emission scanning electron microscope (Leo S360, Cambridge Instruments, Cambridge, UK) primarily at an accelerating voltage of $5 \mathrm{kv}$ which could be increased where necessary to identify constituents below the surface.

\section{RESULTS \& DISCUSSION}

\subsection{TESTING DATA}

\section{Lab Scale Testing}

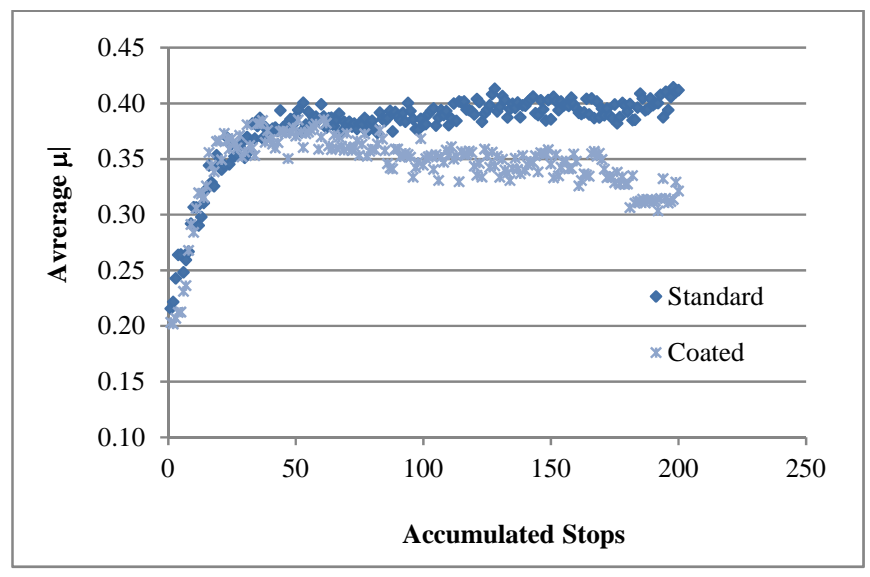

Figure 2 - Lab scale testing results of the standard versus coated small scale samples, against organic pads

Considering the data for the standard sample initially, the values of averaged coefficient of friction $(\mu)$ throughout the test show little variation and a clear trend is identifiable. It is observed that initial $\mu$ is around $\sim 0.22$ and rises quickly to $\sim 0.35$ over the first 20 braking stops; $\mu$ then continues to rise steadily for the remainder until the test finishes at 200 stops at $\sim 0.40$.

Comparing this with the coated sample, again the values of $\mu$ show little variation throughout the test regime, and a clear trend is identifiable. Initial $\mu$ is lower at $\sim 0.20$ but has risen to $\sim 0.37$ within the same period. This remains stable from $20-80$ stops. At this point $\mu$ falls to $\sim 0.35$, where again, it remains stable from $80-170$ stops. At this point it falls slightly again to $\sim 0.32$ where it remains to 200 stops.

The data show that the discs follow similar trends for the initial braking stops, with the coated disc reaching a higher $\mu$ value from fewer applications. The standard sample then follows a steadily rising value through the remainder of the test, whereas the coated sample shows a stepped falling $\mu$ where it appears stable at each step change. As a preliminary test this indicates that this coating has shown marginal improvement in the bedding performance, and suffers from a stable and slowly declining performance thereafter. 


\section{Full Scale Testing}

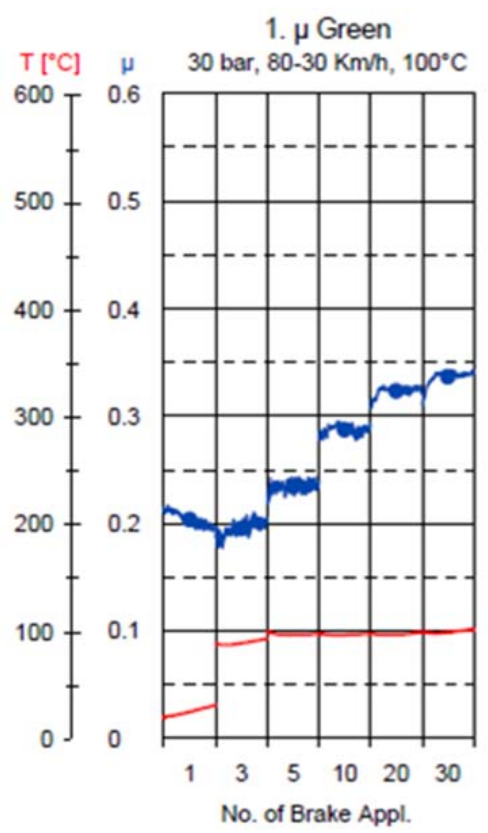

1. $\mu$ Green

30 bar, $80-30 \mathrm{Km} / \mathrm{h}, 100^{\circ} \mathrm{C}$

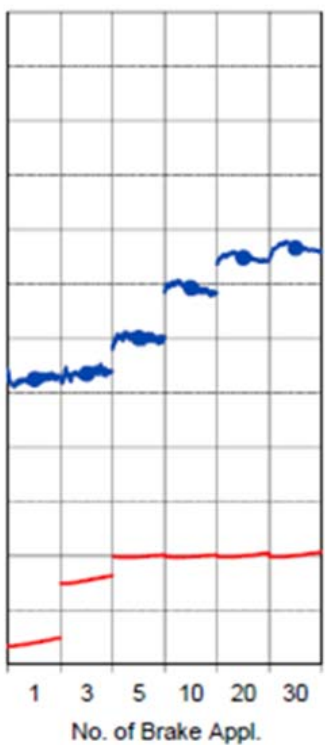

Figure 3 - Full scale testing results; green section standard (left) compared with coated (right) rotors

Figure 3 shows the green performance for the friction couples for both, whilst both rotors display similar trends of rising $\mu$ through this section, the standard sample indicates a trend of falling $\mu$ starting from 0.20 for the first 3 stops, and then rises steadily to a final value of 0.34 after 30 braking stops. The coated sample shows a steadily rising $\mu$ throughout, starting at 0.26 and rising steadily to 0.35 within 10 braking stops, and finishes at a stabilized level of $\sim 0.37$.

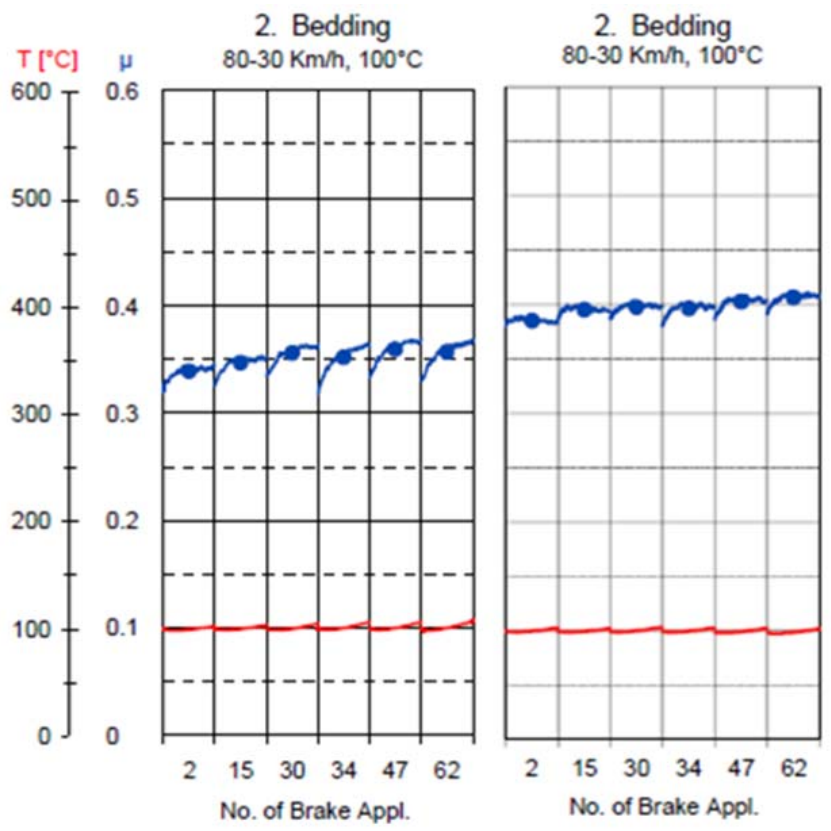

Figure 4 - Full scale testing results; bedding section standard (left) compared with coated (right) rotors

Page 4 of 9 
During the bedding section $\mu$ for the standard sample is fairly stable at $\sim 0.35$, and the coated rotor similarly stable at $\sim 0.40$. Looking at the in-stop $\mu$ traces above the standard rotor has a rising $\mu$ trend through each braking stop, where the coated rotor shows a more stabilized friction level throughout the each stop.

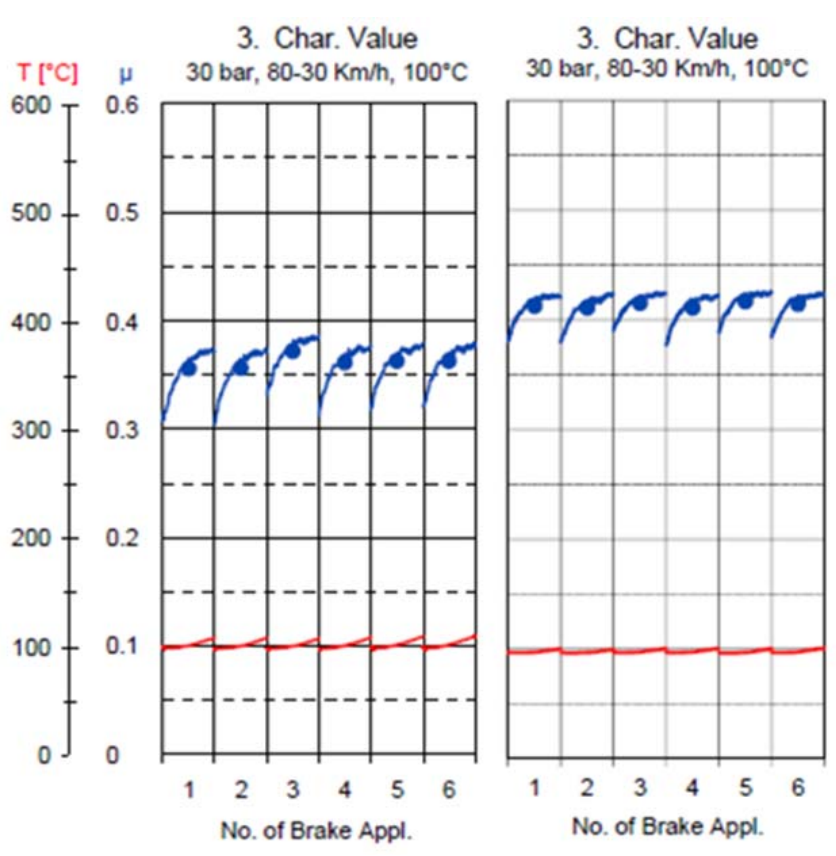

Figure 5 - Full scale testing results; post-bedding characteristic section of standard (left) compared with coated (right) rotors

The characteristic traces show that $\mu$ is stable around $\sim 0.36$ for the standard sample, with a $\mu$ variation through each stop of $\sim 0.06$; the coated sample has a higher stable value of $\sim 0.41$, with lesser variation of $\sim 0.04$. There also appears to be less fluctuation (chatter) of the $\mu$ trace compared with the standard sample.

The results from this first section of the test cycle indicate that the coated disc has bedded faster, to a higher level, with more stable friction performance within each stop. 


\subsection{FRICTION SURFACE CHARACTERISATION}

a)
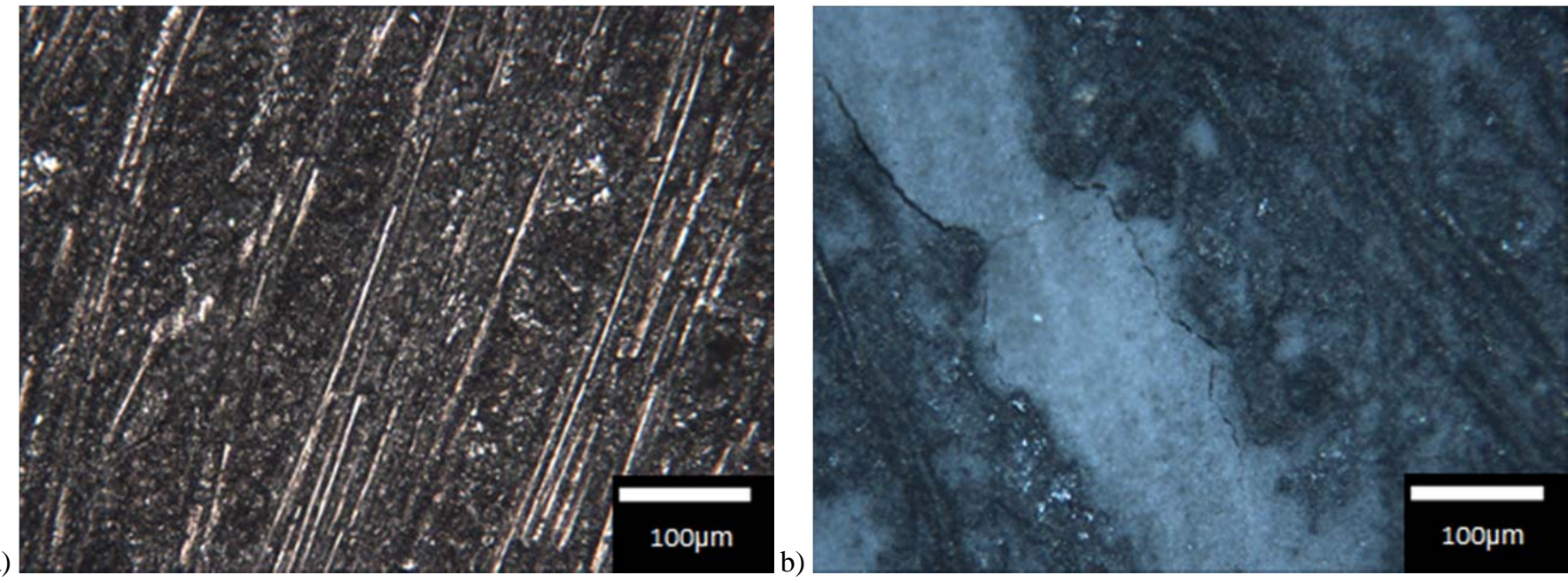

Figure 6 - Optical microscopy images comparing the a) standard and b) coated small scale samples prior to friction testing
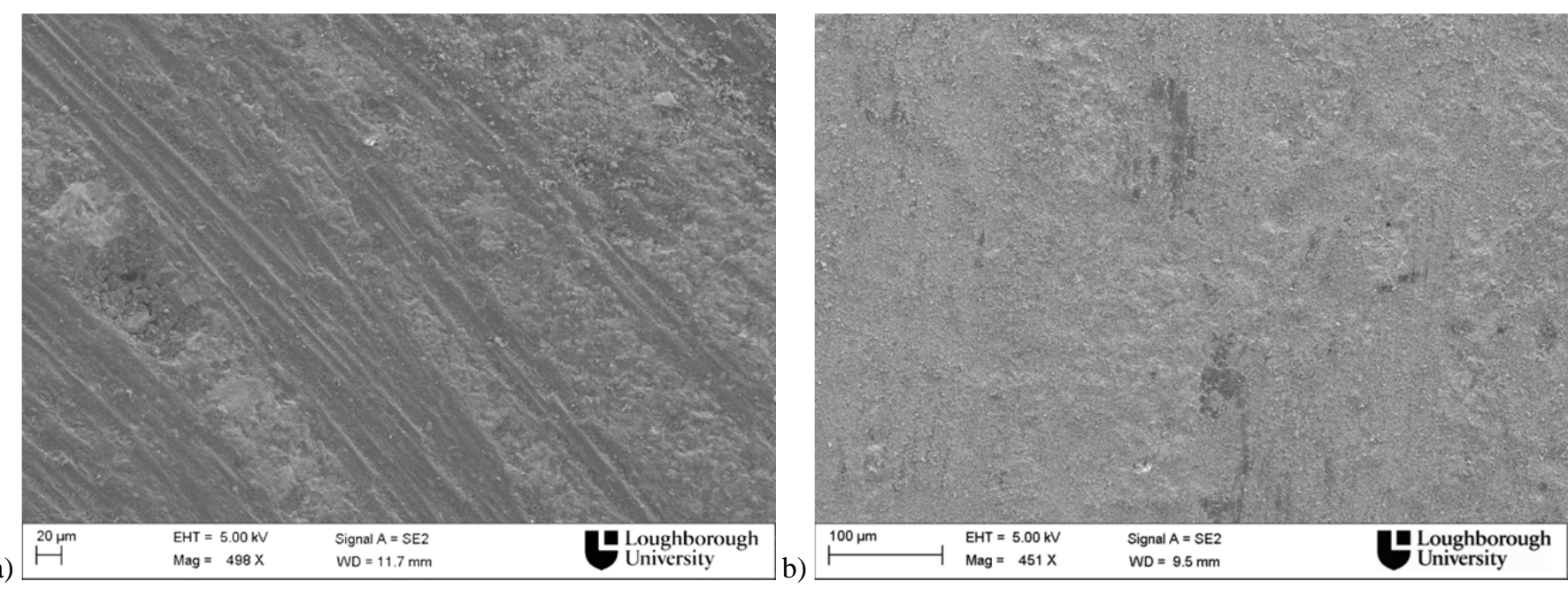

Figure 7 - SEM images comparing the a) standard with the b) coated samples prior to friction testing

The images of the standard sample prior to friction testing show regions of $\mathrm{C}_{\mathrm{f}} / \mathrm{C}$ bundles, interspersed with ceramic regions composed of predominantly $\mathrm{SiC}$ and $\mathrm{Si}$ pools. The ceramic regions are rough with some voids, presumed to be introduced from the removal of ceramic material during surface finishing procedures. The $\mathrm{C}_{\mathrm{f}}$ fibers in the bundles have a cylindrical shape to them. Due to the manufacturer specification surface finish the rough surface scatters the reflected light, making optical imaging at this stage difficult. Looking to the coated surface, the milky white regions in Figure 6 are the coating. The OM imaging in figure 6 shows the coating is spread across the surface with the substrate still visible in places. A large void has been in-filled by the coating to produce a smoother surface overall. This is replicated in the SEM imaging of figure 7, which shows the coating as spread across the surface where under OM conditions it appeared clear. 

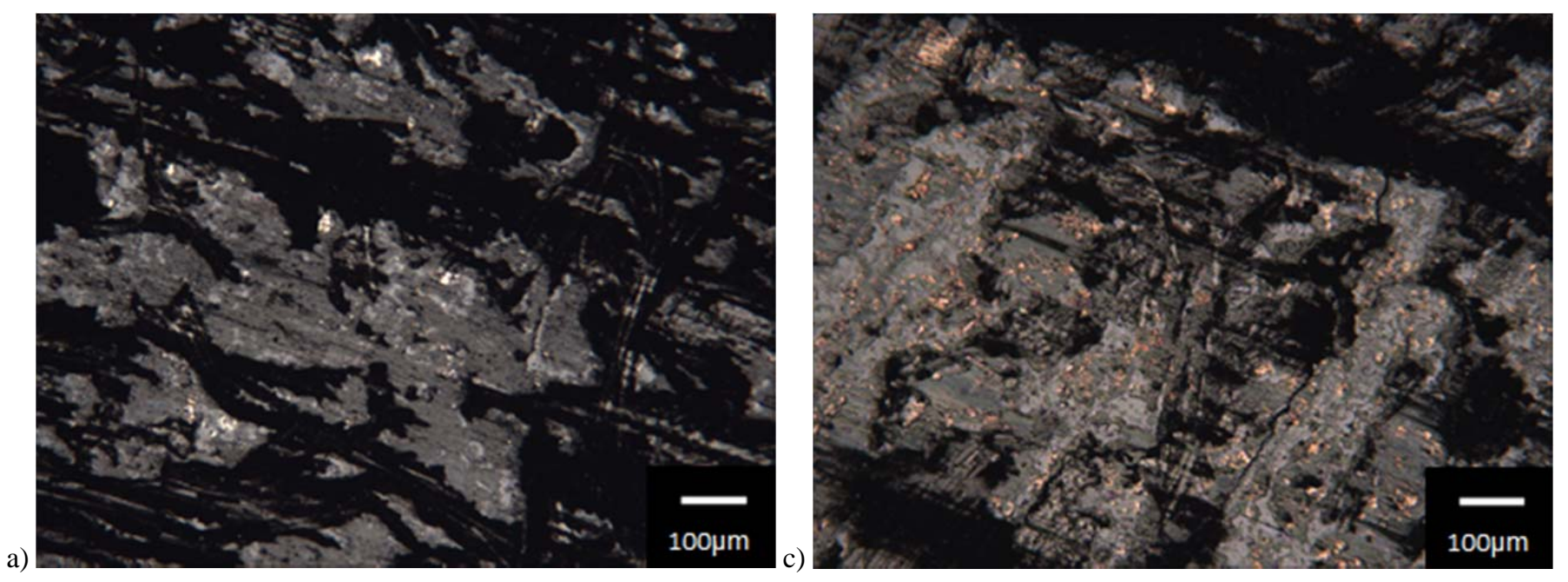

b)
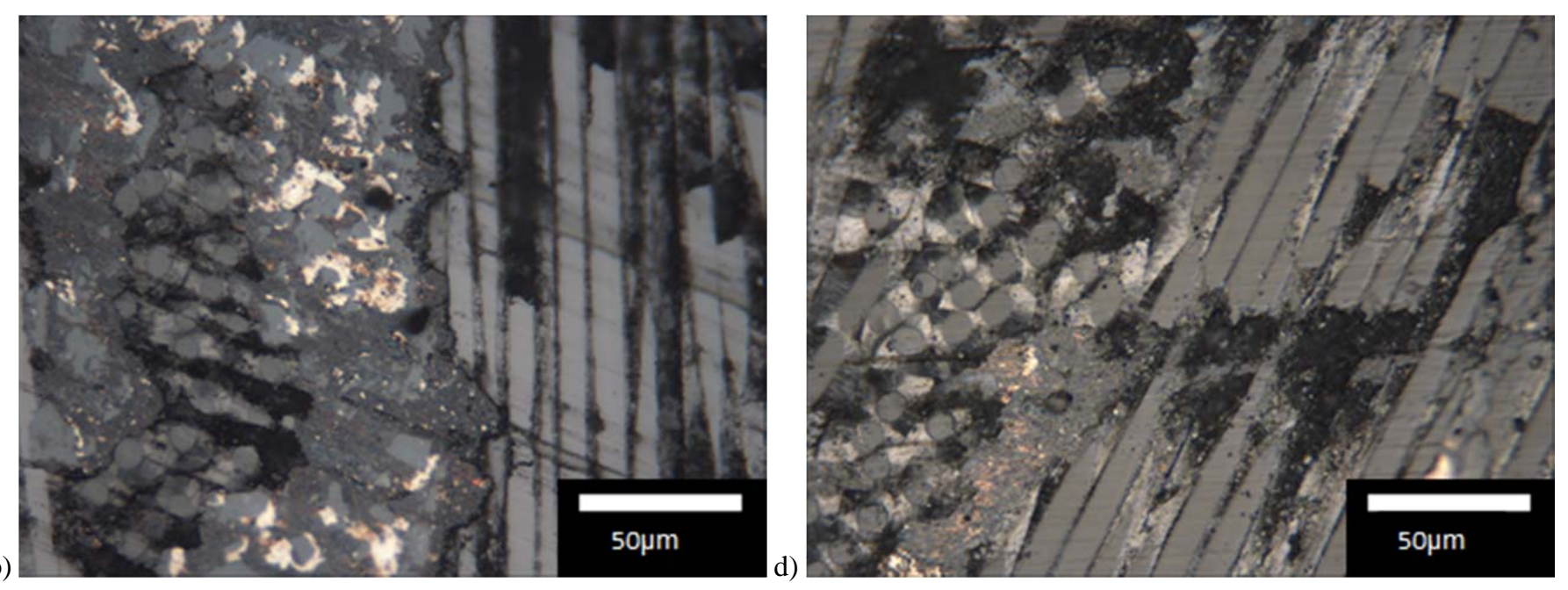

Figure 8 - Optical microscopy images at low and high magnification of the friction surfaces of the a), b) standard and c), d) coated small scale samples after 200 braking stops
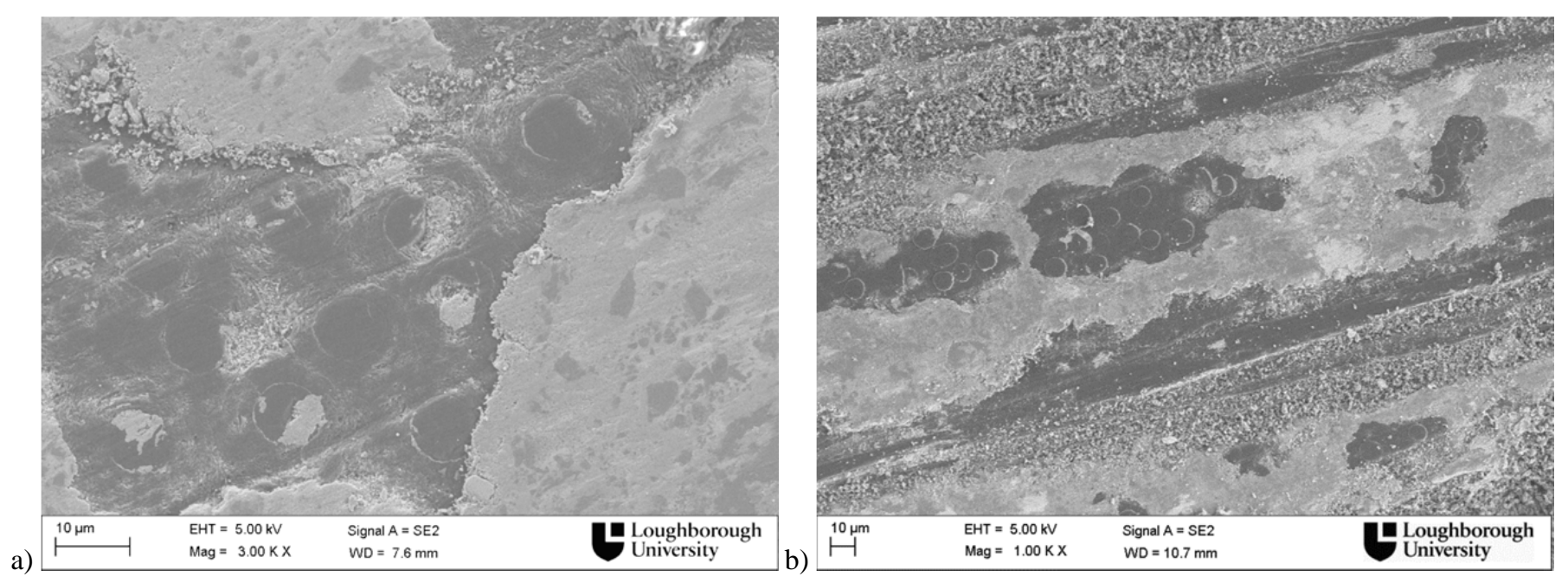

Figure 9 - SEM images of the friction surface of the a) standard, and b) coated, small scale samples after 200 braking stops

Page 7 of 9 
The images in figures 8 \& 9 show the friction surface of both standard and coated samples to be vastly changed after 200 braking stops. It can be seen that a third body layer has formed across some regions of the surface. At higher magnifications it is clear that there is much wear of the $\mathrm{C}_{\mathrm{f}} / \mathrm{C}$ regions, to the point that they are now very smooth in places. Other regions are pitted or full of voids, and are filled with loose debris. Under OM conditions these appear as dark regions where the light has been scattered, and are clearer under SEM conditions.

The third body layer appears to be forming primarily in the ceramic regions, with little spread across the $\mathrm{C}_{\mathrm{f}} / \mathrm{C}$ regions. There is little to differentiate the coated from the uncoated samples in terms of TBL formation.

a)
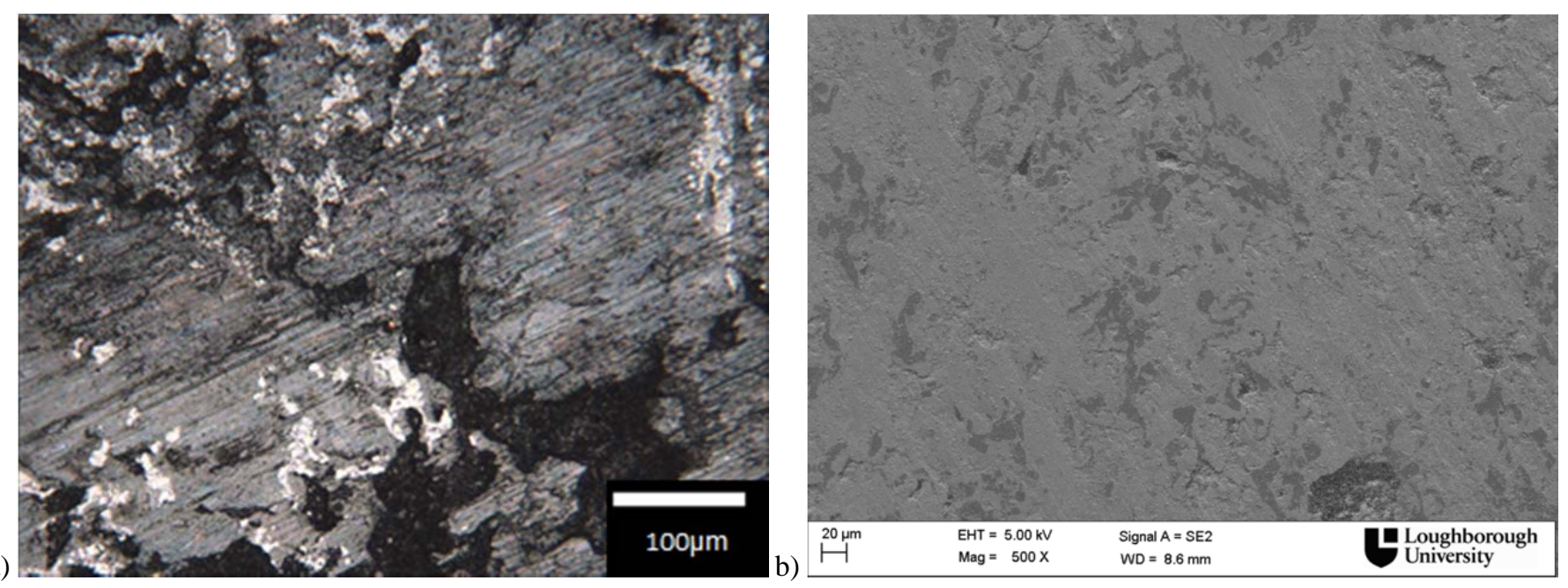

Figure $10-a) O M$ and b) SEM imaging of core samples from full scale coated disc after full dynamometer test

As can be seen in figure 10 the TBL is well deposited across the surface of the disc. EDS mapping analysis of the layer at 5kv shows the presence of the three primary constituents of the original coating throughout the TBL, along with ferrous and non-ferrous metal elements and strong quantities of oxygen. By increasing the accelerating voltage of the SEM, it is possible to identify the elements present at varying depths through the layer. Mapping at $10 \mathrm{kv}$ indicates a stronger presence of the coating elements. At 20kv the elements found are predominantly those of the substrate material, i.e. $\mathrm{C}$ and $\mathrm{Si}$.

The presence of the coating elements indicates strongly that the coating has enabled the formation of the TBL, and the presence of the metal elements and strong oxygen peaks indicates that the TBL layer is primarily formed with metal oxides mixed with the coating layers. The greater presence of the coating constituents at a higher accelerating voltage is a sign that any bonding between the TBL and the substrate is reinforced by the coating.

It is well accepted that a well bonded and deposited TBL at the surface of a friction rotor is required for good, stable and consistently predictable friction performance. That this coated rotor has shown improved bedding behavior, and subsequent friction performance, with a TBL bonded to the substrate validates this understanding. The presence of the coating within the TBL after the full AK master test strongly indicates that these coatings can be utilized to improve friction performance for a longer term than simply the initial bedin process.

\section{COMMENTARY AND SUMMARY}

The results of the small scale dynamometer testing indicate that there is potential for improved bedding performance from the addition of a formulated thin film coating. Subsequent performance is dependent on the successful bonding of the forming TBL to the substrate, which in this case, has not proven successful. Friction surface characterization shows that the coating has not aided the deposition, or build up, of a TBL. Further revisions of the coating formulations will need to be carried out to improve bedding performance and subsequent TBL retention.

The full scale testing data show that the coating aids bedding and further friction performance significantly. Throughout the testing schedule the coated rotor has a noticeably higher and more stable $\mu$. Friction surface characterization of the coated disc after testing Page 8 of 9 
shows a well deposited TBL layer, with EDS analysis indicating a strong presence of the coating constituents remaining throughout, and particularly near to the interface between the TBL and the substrate.

The standard samples in both situations are reliant upon friction, in the form of heat and pressure, to create wear debris from the pad and rotor. This wear debris is then utilized to form the third body layer through consolidation. Using a specially formulated coating at the surface has shown that by capturing those wear debris in the initial braking stops, and bonding it to the substrate, has reduced the time to bed in and increased the friction level.

Subsequently to this, any hybrid-TBL layer would also form a strong reinforcement surrounding the ceramic regions of the rotor, and cover the weaker $\mathrm{C}_{\mathrm{f}} / \mathrm{C}$ regions. This would relieve some of the pressure acting upon the ceramic peaks, and ensure they withstand friction for a longer period. This would also produce a consistent, reinforced surface for the pad to act against, providing a stable friction surface, whilst also protecting the rotor from potential wear damage. This is shown through the consistent friction improvements through the remainder of the full scale test. There should also be seen additional benefits such as reduced wear rates improved life-cycle usage.

To validate this further a cross-section should be taken through the surface layers and analysed for chemicals to identify regions where the coating is dominant. Continued testing on the small scale dynamometer is underway, and full scale testing is also scheduled to be repeated to understand any potential longevity issues.

There is a disparity in the test performance from the small to large scale dynamometer testing. As a general rule, the test results show similar friction levels throughout, however, the small scale dynamometer indicates a trend of falling $\mu$. The author would hypothesise that this is due to the lack of heat cycling capability in the small scale test rig to ensure the complete chemical reactions as planned.

\section{REFERENCES}

1. Krenkel et al, 'C/C-SiC Composites for Advanced Friction Applications', Advanced Engineering Materials, 2002, 4, No.7

2. Wang \& Wu et al, 'Interaction Between Ceramic Matrix Composite and Organic Pad Materials and its Impact on the Friction Performance’, SAE International, 2011, 2011-01-2350

\section{CONTACT INFORMATION}

Mr Arthur Swarbrick, Department of Materials, Loughborough University, Loughborough, Leicestershire, LE11 3HL, UK.

\section{A.L.Swarbrick@lboro.ac.uk}

Dr Houzheng Wu, Department of Materials, Loughborough University, Loughborough, Leicestershire, LE11 3HL, UK.

H.Wu2@lboro.ac.uk

\section{ACKNOWLEDGMENTS}

The author would like to acknowledge the support of the Technology Strategy Board in their funding of this research, and the support of Surface Transforms PLC and Federal Mogul Ltd in their support financially and in materials supply. 